Fourth International Conference on Sustainable Construction Materials and Technologies http://www.claisse.info/Proceedings.htm

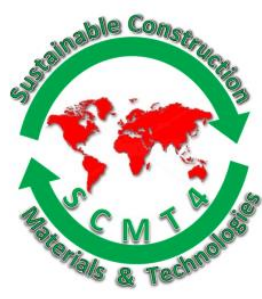

SCMT4

Las Vegas, USA, August 7-11, 2016

\title{
Alkali-Activated Fly Ash Manufactured with Multi-stage Microwave Curing
}

\author{
Shi Shi ${ }^{1 a}$, Hui Li ${ }^{2 a}$, Matthias Fabian ${ }^{3 a}$, Tong Sun ${ }^{3 b}$, K.T.V. Grattan ${ }^{3 c}$, Delong Xu ${ }^{2 b}$, \\ P.A.M. Basheer ${ }^{4}$, and Yun Bai ${ }^{1 b *}$
}

${ }^{1}$ Department of Civil, Environmental and Geomatic Engineering, University College London, WC1E 6BT, U.K. ${ }^{1 a}$ Email: 〈shi.shi.11@ucl.ac.uk>, ${ }^{1 b}$ Email :<yun.bai@ucl.ac.uk>

${ }^{2}$ Institute of Powder Engineering, College of Materials and Mineral Resources, Xi'an University of Architecture and Technology, Shaanxi Province Key Laboratory of Construction Technology, 710055, P.R. China, ${ }^{2 a}$ Email: <lihui@xauat.edu.cn>; ${ }^{2 b}$ Email: $<d l x u @ x a u a t . e d u . c n>$.

${ }^{3}$ School of Mathematics, Computer Science and Engineering and ${ }^{b}$ City Graduate School, City University London, EC1V OHB, U.K. ${ }^{3 a}$ Email: <matthias.fabian.1@city.ac.uk>; ${ }^{3 b}$ Email: 〈t.sun@city.ac.uk>;

${ }^{3 c}$ Email: $<k . t . v . g r a t t a n @ c i t y . a c . u k>$

${ }^{4}$ School of Civil Engineering, University of Leeds, LS2 9JT, U.K., Email:<p.a.m.basheer@leeds.ac.uk>

\begin{abstract}
Alkali-activated fly ash (AAFA) manufactured with conventional thermal curing $\left(85^{\circ} \mathrm{C}\right)$ shows comparative mechanical properties to Portland cement (PC) based system, demonstrating its potential as a future low-carbon and environmentally friendly alternative cementitious material. However, the environmental benefit which could have been achieved from the low carbon nature of AAFA is often offset by the higher energy consumption from thermal curing. Since microwave heating is usually considered as a low-energy and low-carbon heating method, some pilot attempts have been made in the literature to cure AAFA with domestic microwave ovens. However, due to the lack of control on the temperature and humidity in domestic microwave ovens, splashing of fresh AAFA pastes and microcracks of hardened AAFA are two main reasons causing the unsatisfactory performance of microwave cured AAFA.
\end{abstract}

In this study, a custom-made microwave oven equipped with proportional-integral-derivative (PID) control was employed to cure AAFA samples. The microwave power was automatically regulated through the real-time temperature feedback from the fibre Bragg grating (FBG) sensor embedded in the AAFA sample. The microwave curing regime consisted of four curing stages at four different temperatures, namely $65^{\circ} \mathrm{C}, 85^{\circ} \mathrm{C}, 105^{\circ} \mathrm{C}$ and $125^{\circ} \mathrm{C}$. The similar temperature profile was applied on the AAFA cured in a conventional thermal oven. Compressive strength, reaction products and microstructure of AAFA samples with two curing methods were examined by the analytical techniques of XRD, FTIR, NMR, MIP and SEM respectively. The results showed that AAFA under microwave curing exhibited higher compressive strength with less energy consumption than that under the conventional thermal curing. The microwave curing favoured the formation of Al-rich N-A-S$\mathrm{H}$ gel in AAFA and a more compacted microstructure. 


\section{INTRODUCTION}

Alkali-activated fly ash (AAFA), consisting of fly ash and alkaline activators, shows equivalent cementitious properties to Portland cement (PC). However, different from PC system, the main reaction product of AAFA is three dimensional amorphous sodium aluminosilicate hydrate $(\mathrm{N}-\mathrm{A}-\mathrm{S}-\mathrm{H}$ gel) along with a small quantity of zeolites (Palomo et al., 1999). Compared to PC system, it has been claimed that AAFA produces lower $\mathrm{CO}_{2}$ emission, consumes less energy and possesses superior durability (Bakharev, 2005a, Fernandez-Jimenez et al., 2006a). However, the strength development of AAFA is very slow under room temperature and thermal curing is essential for the initiation of the chemical reaction and then subsequent strength gain (Puertas et al., 2003, Criado et al., 2005). Currently, the prevailing curing method for AAFA is thermal curing at $85^{\circ} \mathrm{C}$, which normally takes more than 8 hours to obtain an early strength of above $20 \mathrm{MPa}$ (Criado et al., 2005). The main drawback of this thermal curing is its high energy consumption, offsetting the environmental benefits which could be obtained from AAFA itself.

Compared with conventional thermal heating, such as thermal oven, it has been generally agreed that microwave is a low energy heating source. The dominant heating mechanism of conventional thermal curing is thermal conduction from the surface to the core of the samples, which is slow and may generate thermal gradient inside the sample (Holman, 2002). Consequently, it can potentially lead to thermal cracks, affecting the strength development. Microwave curing is different from conventional thermal curing. Under the alternating electromagnetic field of microwave, dipolar molecules of dielectric materials can vibrate and, thus, generate frictions between the molecules which then convert microwave energy into heat energy instantly and volumetrically (Metaxas; and Meredith, 1983). As all the components in concrete, such as water, cement and aggregate are dielectric materials, concrete itself can be heated by microwave effectively (Ong and Akbarnezhad, 2015).

Some pilot research have been reported in the literature on using microwave as an alternative heating source to cure cement or concrete products (Wu et al., 1987, Leung and Pheeraphan, 1997). Their results indicated that microwave is a potential low energy technique for manufacturing concrete and both its curing duration and energy consumption can be reduced dramatically. However, the research on using microwave to cure AAFA is still scarce. Somaratna et al. (2010) are possibly the only pioneers to cure AAFA mortar in a domestic microwave oven. They found that the compressive strength of AAFA could reach $58 \mathrm{MPa}$ after 120 minutes microwave curing, while only $38 \mathrm{MPa}$ could be obtained after 48 hours thermal curing at $75^{\circ} \mathrm{C}$ in a thermal oven. Whilst all these previous research have indicated that microwave is a potential low-energy curing technique, one of the main issues facing the previous studies is the lack of an appropriate curing regime and accurate temperature and humidity control during the microwave curing process due to the employment of domestic microwave ovens in their studies, which have caused splashing of fresh samples as well as overheating and thermal cracks inside the hardened samples (Wu et al., 1987). Different from the previous research, a custom-made microwave oven with multi-stage microwave curing regime was employed in this study to cure AAFA. The effects of the proposed multi-stage microwave curing regime on the compressive strength, energy consumption, reaction products and microstructure of AAFA are reported and also compared with those of the AAFA manufactured in a conventional thermal oven in this paper.

\section{EXPERIMENTAL}

Materials and custom-made microwave oven. Class F fly ash was used in this study. The chemical composition of fly ash is given in Table 1. Figure 1 shows the SEM image of fly ash particles. The mean particle size of the fly ash is $17.93 \mu \mathrm{m}$ and the percentage of particles smaller than $45 \mu \mathrm{m}$ is $88.55 \%$. Sodium hydroxide $(\mathrm{NaOH})$ of industrial grade with a purity of $95 \%$ supplied by ReAgent, UK was used as an activator. 
Table 1. Chemical composition of fly ash (wt/\%)

\begin{tabular}{|c|c|c|c|c|c|c|c|c|c|c|c|}
\hline $\mathrm{SiO}_{2}$ & $\mathrm{Al}_{2} \mathrm{O}_{3}$ & $\mathrm{Fe}_{2} \mathrm{O}_{3}$ & $\mathrm{CaO}$ & $\mathrm{Na}_{2} \mathrm{O}$ & $\mathrm{MgO}$ & $\mathrm{K}_{2} \mathrm{O}$ & $\mathrm{SO}_{3}$ & $\mathrm{P}_{2} \mathrm{O}_{5}$ & $\mathrm{TiO}_{2}$ & Other & $\mathrm{LOI}$ \\
\hline 49.29 & 30.55 & 5.55 & 5.96 & 0.74 & 0.81 & 1.38 & 0.63 & 0.21 & 1.08 & 0.33 & 1.87 \\
\hline
\end{tabular}

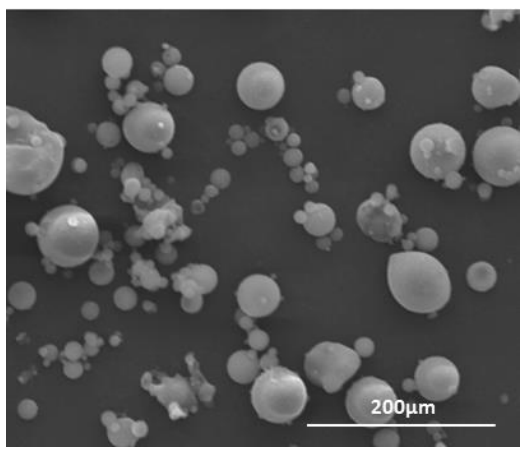

\section{Figure 1. SEM image of Class F fly ash}

The custom-made microwave oven was manufactured by Industrial Microwave System Ltd, UK. The microwave power can be varied from 0 to 1000 Watts continuously. Equipped with fibre Bragg grating (FBG) sensor, the temperature changes inside the sample during the microwave curing process can be recorded and the temperature feedback is then used to regulate the microwave power under proportionalintegral-derivative (PID) control.

Preparation of the sample. $8 \mathrm{M} \mathrm{NaOH}$ solution was used in this work to activate fly ash and the $\mathrm{NaOH}$ solution to fly ash ratio was 0.33 by mass. Immediately after mixing, the AAFA mixtures were cast into tailored-made plastic moulds, and the fresh AAFA paste samples $(25 \mathrm{~mm} \times 25 \mathrm{~mm} \times 25 \mathrm{~mm})$ were then subjected to different accelerated curing, namely, conventional thermal curing and multi-stage microwave curing. The energy consumption during both curing processes was obtained from the power meters attached to each curing equipment.

The details of each accelerated curing are given below:

- Multi-stage microwave curing (MW): The curing process consisted of four stages (RH>90\%) and lasted for different durations, in which the curing temperatures at each stage were $65^{\circ} \mathrm{C}$ (duration at $65^{\circ} \mathrm{C}, \mathrm{t}_{1}: 35$ minutes), $85^{\circ} \mathrm{C}$ (duration at $85^{\circ} \mathrm{C}, \mathrm{t}_{2}: 35$ minutes), $105^{\circ} \mathrm{C}$ (duration at $105^{\circ} \mathrm{C}, \mathrm{t}_{3}: 35$ minutes) and $125^{\circ} \mathrm{C}$ (duration at $125^{\circ} \mathrm{C}, \mathrm{t}_{4}: 85$ minutes) respectively. The curing regime is shown in Figure 2.

- Conventional thermal curing (OV): A similar temperature and curing duration profile as employed in the microwave curing was applied in the conventional thermal curing as a control in the current study;

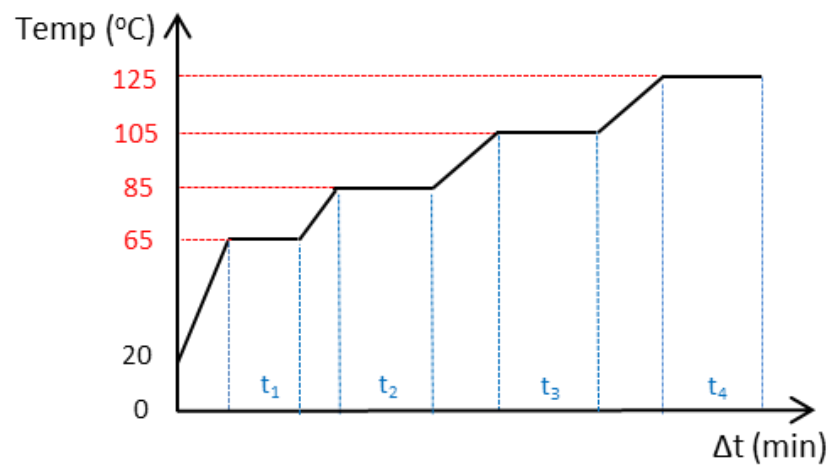

Figure 1. Multi-stage microwave curing regime for manufacturing AAFA 
Tests. The compressive strength of AAFA samples was tested 2 hours after the accelerated curing when the samples were cooled down to room temperature. Reaction products were characterised by means of Xray Diffraction (XRD), Fourier Transform Infrared spectroscopy (FTIR) and Nuclear Magnetic Resonance spectroscopy (NMR). The microstructure of hardened AAFA was studied by Mercury Intrusion Porosimetry (MIP) and Scanning Electron Microscopy (SEM).

\section{RESULTS}

Compressive strength and energy consumption. The compressive strength gained after the accelerated curing as well as the energy consumption incurred during the two curing methods are shown in Table 2. With 4.5 hours multi-stage curing, the MW AAFA obtained higher strength than the OV AAFA, i.e. 35.66 $\mathrm{MPa}$ as compared to $28.10 \mathrm{MPa}$, which is around $27 \%$ increase. More importantly, it can be seen that the energy consumption per strength gained $(\mathrm{kJ} / \mathrm{MPa})$ is only $191.81 \mathrm{KJ} / \mathrm{MPa}$ for the MW AAFA whereas this is $330.92 \mathrm{KJ} / \mathrm{MPa}$ for the OV AAFA, which indicates that a $42 \%$ reduction in the energy consumption has been achieved from the multi-stage microwave curing compared to the conventional thermal curing.

Table 2. Compressive strength and energy consumption of AAFA with two curing methods

\begin{tabular}{|c|c|c|c|c|c|}
\hline Sample & Curing method & $\begin{array}{c}\text { Duration } \\
\text { (hour) }\end{array}$ & $\begin{array}{c}\text { Total energy } \\
\text { consumption (kJ) }\end{array}$ & $\begin{array}{c}\text { Compressive } \\
\text { strength (MPa) }\end{array}$ & $\begin{array}{c}\text { Energy } \\
\text { consumption } \\
\text { (kJ/MPa) }\end{array}$ \\
\hline OV AAFA & Electric oven & 4.5 & 9299 & 28.10 & 330.92 \\
\hline MW AAFA & Microwave oven & 4.5 & 6840 & 35.66 & 191.81 \\
\hline
\end{tabular}

XRD. Figure 3 presents the XRD spectra of the raw fly ash and the two AAFA samples. The hump appeared in the raw fly ash represents the amorphous phase (as indicated at $17-33^{\circ} 2 \theta$ ). The peaks of crystalline phases, such as quartz, mullite and hematite were also detected which is similar to those reported in the literature (Criado et al., 2007a, Kovalchuk et al., 2007). After alkali activation, the area below the hump representing the amorphous phase decreased in both AAFA samples, indicating that the amorphous phase in the raw fly ash was dissolved and took part in the alkali activation (Palomo et al., 1999, Criado et al., 2007a). In addition, two new zeolitic phases were identified in both OV AAFA and MW AAFA. One new zeolitic phase, as indicated by the new peaks appeared at $13.8^{\circ}$ and $24^{\circ} 2 \theta$ were also attributed to hydroxysodalite. The other new zeolitic phase identified at $34.2^{\circ} 2 \theta$ was assigned to chabazite-Na. These results were in good agreement with those findings reported in the literature by other researchers (Criado et al., 2007a, Bakharev, 2005b).

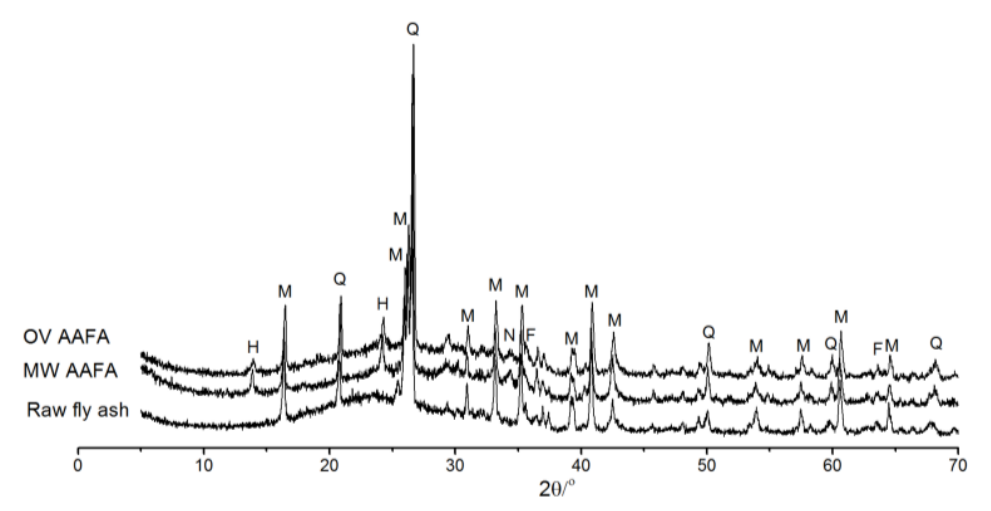

Figure 3. XRD spectra of raw fly ash and AAFA samples, Q-quartz, M-mullite, F-hematite, H-hydroxysodalite, N-chabazite-Na 
FTIR. Figure 4 depicts the FTIR spectra of the raw fly ash and the two AAFA samples. The presence of quartz and mullite in the raw fly ash was responsible for the bands appeared at $791 \mathrm{~cm}^{-1}$ and $548 \mathrm{~cm}^{-1}$ respectively. In addition, a wide band associated with $\mathrm{T}-\mathrm{O}(\mathrm{T}=\mathrm{Al}, \mathrm{Si})$ asymmetric stretching vibrations from the amorphous phase can be observed at $1037 \mathrm{~cm}^{-1}$ in the raw fly ash. After alkali activation, the T$\mathrm{O}$ band became sharper and shifted towards lower frequencies at $978 \mathrm{~cm}^{-1}$ in OV AAFA and $974 \mathrm{~cm}^{-1}$ in MW AAFA respectively, which is considered as the fingerprint of the formation of N-A-S-H gel in AAFA (Fernandez-Jimenez and Palomo, 2005, Criado et al., 2007b). It is interesting to find that the T-O band in the MW AAFA shifted towards even lower frequency than that in the OV AAFA. As the lower frequency of the T-O band in the AAFA indicates more Al tetrahedra is positioned in the N-A-S-H gel (Fernandez-Jimenez and Palomo, 2005, Criado et al., 2007b), this finding implies that the N-A-S-H gel formed in the AAFA with microwave curing could be more Al-rich than that formed with conventional thermal curing.

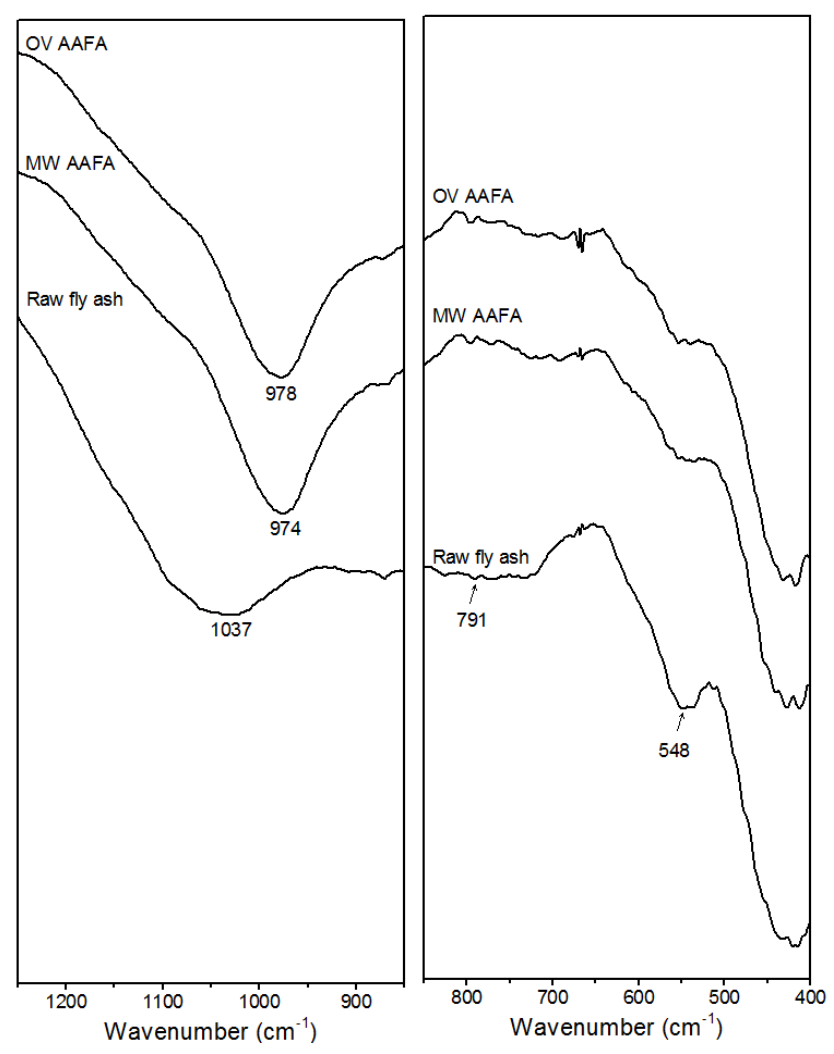

Figure 4. FTIR spectra of raw fly ash and AAFA samples

$\mathbf{S i}^{29}$ NMR . The ${ }^{29} \mathrm{Si}$ NMR spectra of the raw fly ash and the two AAFA samples are illustrated in Figure 5. The deconvolution of the spectra can reveal different components in the fly ash and AAFA samples. In the raw fly ash, the peaks detected at $-85.0 \mathrm{ppm},-93.3 \mathrm{ppm},-98.3 \mathrm{ppm},-101.6 \mathrm{ppm}$ and $-105.3 \mathrm{ppm}$ can be attributed to the different Si environments in the amorphous phase (Fernandez-Jimenez et al., 2006b, Criado et al., 2008). After alkali activation, the broad resonance band in the raw fly ash shifted in both AAFA samples, indicating the reaction products formed in the AAFA samples (Palomo et al., 2004, Criado et al., 2008). The chemical shifts which can be ascribed to various $\mathrm{Q}^{4}(\mathrm{mAl})$ units in AAFA samples are given in Table 3. It can be seen that the chemical shift of $\mathrm{Q}^{4}(4 \mathrm{Al})$ and $\mathrm{Q}^{4}(3 \mathrm{Al})$ in MW AAFA are less negative than that in OV AAFA, indicating again more $\mathrm{AlO}_{4}$ units were involved in the structure of N-A-S-H gel. 

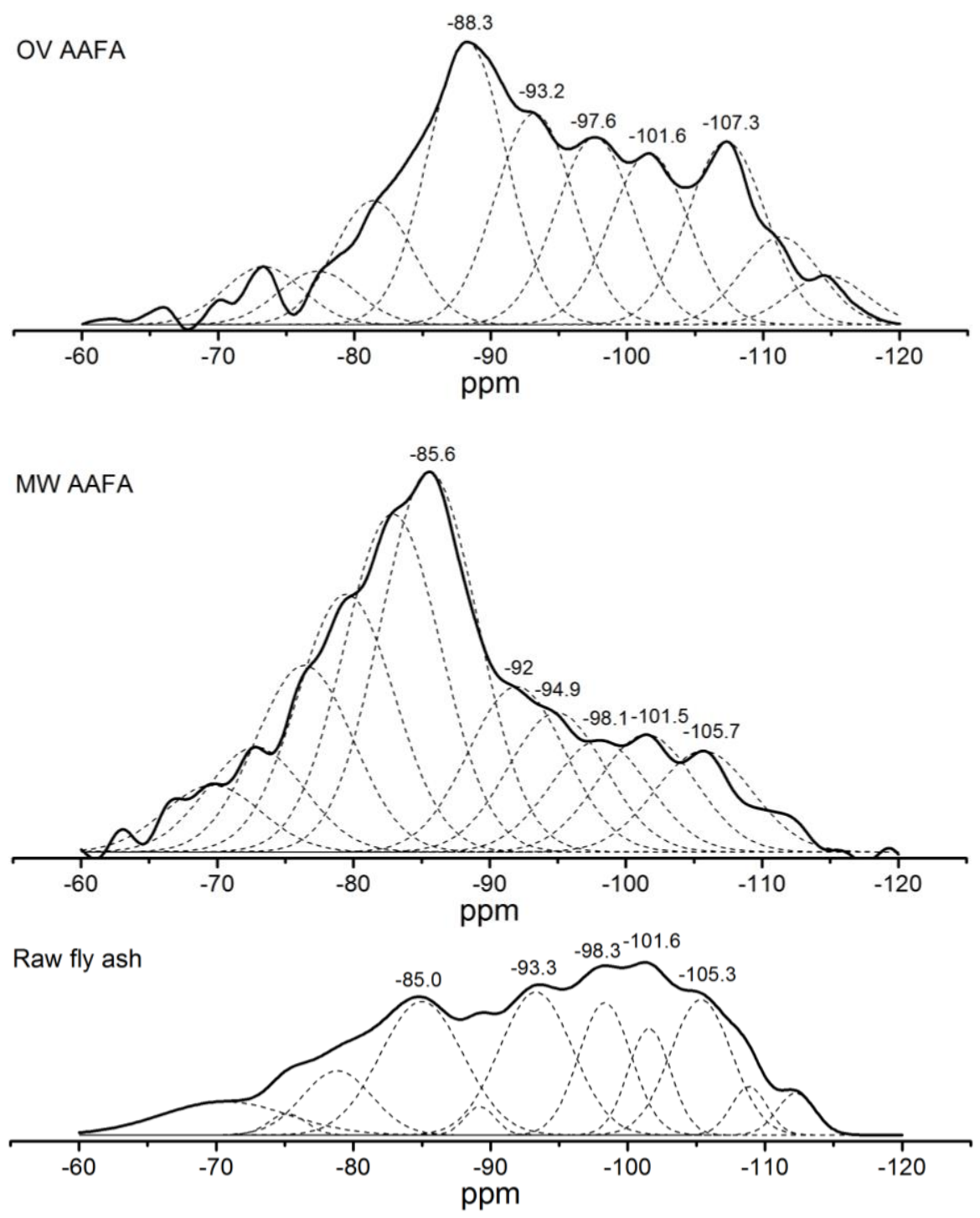

Figure 5. ${ }^{29} \mathrm{Si}$ NMR spectra of raw fly ash and AAFA samples

Table 3. ${ }^{29} \mathrm{Si}$ signals of N-A-S-H gel formed in OV AAFA and MW AAFA

\begin{tabular}{|c|c|c|c|c|c|}
\hline \multirow{2}{*}{ Sample } & $\mathrm{Q}^{4}(4 \mathrm{Al})$ & $\mathrm{Q}^{4}(3 \mathrm{Al})$ & $\mathrm{Q}^{4}(2 \mathrm{Al})$ & $\mathrm{Q}^{4}(1 \mathrm{Al})$ & $\mathrm{Q}^{4}(0 \mathrm{Al})$ \\
\cline { 2 - 6 } & -88 & $-93 /-94$ & -98 & $-103 /-104$ & -108 \\
\hline OV AAFA & -88.3 & -93.2 & -97.6 & -101.6 & -107.3 \\
\hline MW AAFA & -85.6 & $-92 /-94.9$ & -98.1 & $-101.5 /-105.7$ & - \\
\hline
\end{tabular}

MIP. Figure 6a shows the curves of cumulative volume of mercury intruded into the two AAFA samples, which is in line with the results given in Table 4 that OV AAFA obtained a higher total porosity (32.11\%) than MW AAFA (20.99\%). Figure $6 \mathrm{~b}$ gives further details of the pore size distribution of the two AAFA samples. It can be seen that there are two peaks representing the ranges of the pores in the OV AAFA, which could be assigned to gel pores $(10-140 \mathrm{~nm})$ and capillary pores $(140-1000 \mathrm{~nm})$ respectively (Ma et al., 2013). However, most of the pores in the MW AAFA only fell in one range (140-1000 nm), representing the capillary pores. As indicated in Figure $6 \mathrm{~b}$, with similar capillary pore distribution between OV AAFA and MW AAFA, the main reason contributed to the higher porosity of OV AAFA is the large amount of gel pores in OV AAFA. 


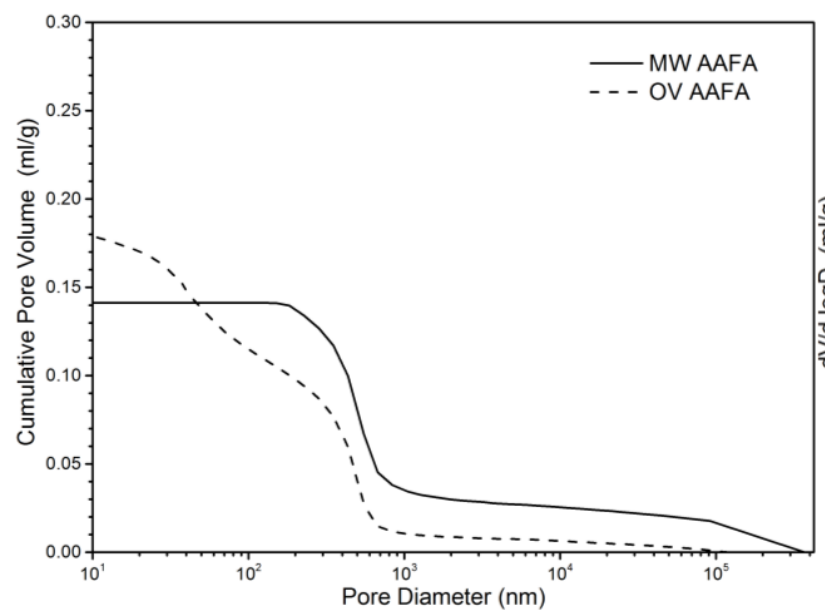

a. Cumulative pore volume vs pore diameter

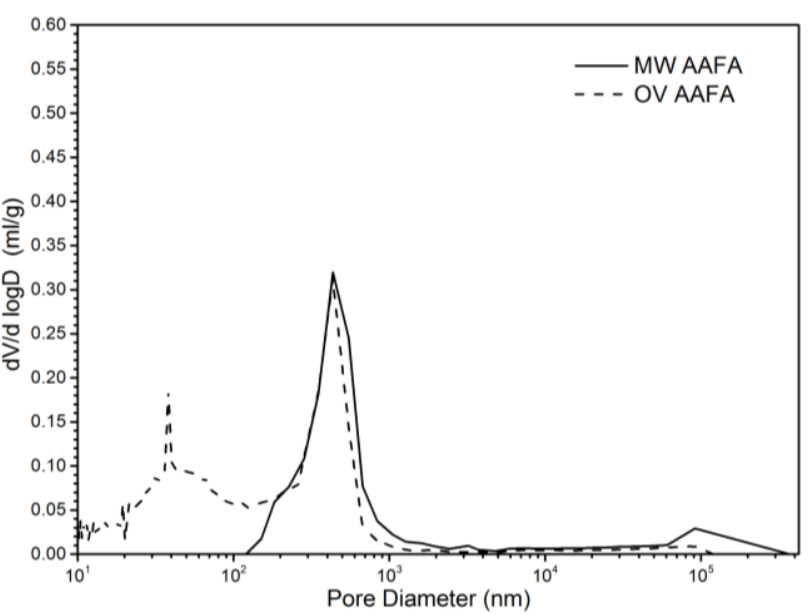

b. Differential pore volume vs pore diameter

Figure 6. Pore size distributions of AAFA samples

Table 4. Total porosities of OV AAFA and MW AAFA

\begin{tabular}{|c|c|}
\hline Sample & Total porosity \\
\hline OV AAFA & $32.11 \%$ \\
\hline MW AAFA & $20.99 \%$ \\
\hline
\end{tabular}

SEM. Figure 7 presents the fractured surface of the two AAFA samples manufactured with different curing methods. Both of them featured heterogeneous microstructure. The OV AAFA showed a more porous structure in comparison with MW AAFA. The reaction products formed on the surface of fly ash particles and in the region between the fly ash particles were also observed in both samples.

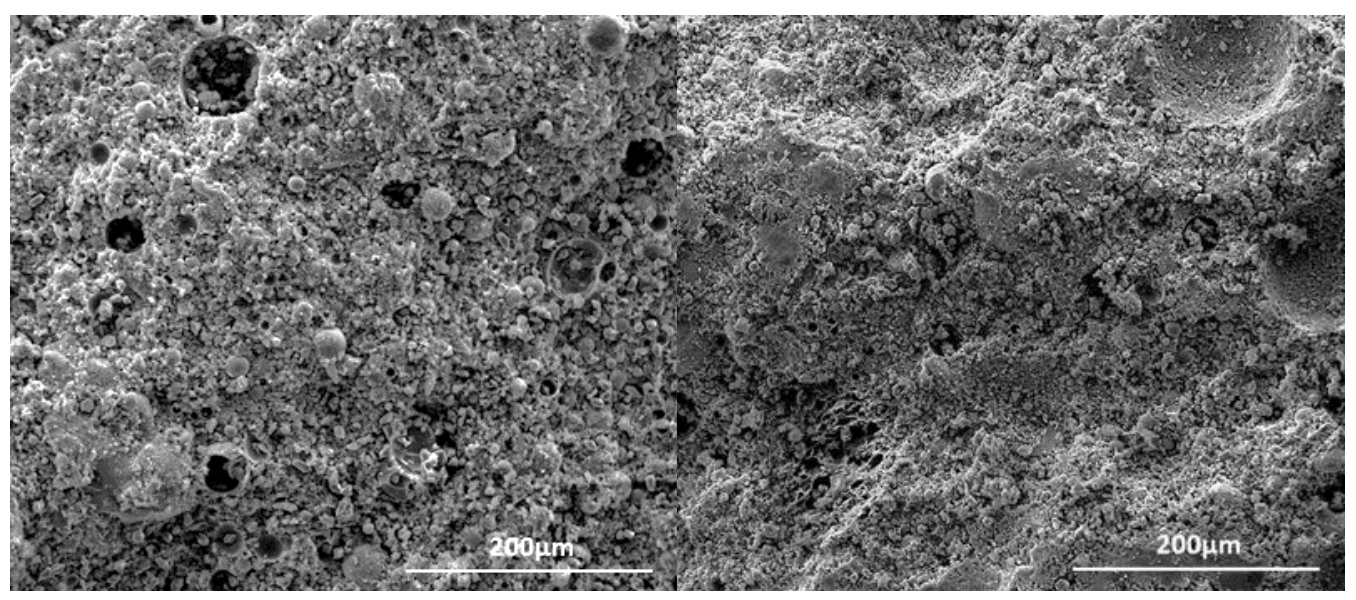

a. OV AAFA

b. MW AAFA

Figure 7. SEM images of AAFA samples

\section{DISCUSSIONS}

In general, alkali activation of fly ash is considered to consist of two stages, namely, dissolution and gelation (Fernandez-Jimenez et al., 2005). It has been agreed that the external heat is essential for the activation of fly ash, particularly with $\mathrm{NaOH}$ as the activator. This could be explained by the activation 
barrier which needs to be overcome with the assistance of external heat before the activation can take place (Bakharev, 2005b). Conventional thermal heating is a slow process relying on heat conduction, whilst microwave can heat up dielectric materials rapidly and volumetrically. The dissolution process can thus be sped up and the reaction rate could be increased by microwave curing due to the high heating efficiency, which has been verified by the higher compressive strength obtained by MW AAFA sample. On the other hand, it seems microwave can also promote the gelation of AAFA as the MW AAFA formed a more compacted microstructure than OV AAFA, which is in line with the strength results.

$\mathrm{N}-\mathrm{A}-\mathrm{S}-\mathrm{H}$ gel, the primary reaction product, contributes to the strength development of AAFA. The strength developed is in proportion to the N-A-S-H gel formed. In the previous research, it was found that the N-A-S-H gel formed in the early stage of alkali activation is Al-rich (Gel 1) and a more stable Si-rich $\mathrm{N}-\mathrm{A}-\mathrm{S}-\mathrm{H}$ gel $(\mathrm{Gel} 2)$ is formed with more silica groups taking part in the gelation process. Compared to Gel 1, the increase of Gel 2 formed is closely related to the mechanical strength rise (Fernandez-Jimenez et al., 2006b). However, both FTIR and NMR results have shown that the N-A-S-H gel formed in MW AAFA is more Al-rich than that formed in OV AAFA, which implies that $\mathrm{AlO}_{4}$ units may have the advantage of absorbing microwave energy over $\mathrm{SiO}_{4}$ units, leading to the formation of Al-rich gel. Nonetheless, it seems that the microwave can facilitate the dissolution of fly ash particles and the formation of denser microstructure which could have compensated the weak bond of Al-rich gel. However, the possible selective absorption of $\mathrm{AlO}_{4}$ units and $\mathrm{SiO}_{4}$ units to microwave needs further investigation.

\section{CONCLUSION}

The following conclusions can be drawn from this study:

- With similar temperature history, AAFA manufactured with microwave curing exhibited higher compressive strength, but less energy consumption than that with the conventional thermal curing.

- The microwave curing favoured the formation of Al-rich N-A-S-H gel in AAFA and a more compacted microstructure.

\section{ACKNOWLEDGEMENT}

Miss Shi Shi is sponsored by China Scholarship Council (CSC) for her study at University College London (UCL, UK). Xi' an University of Architecture and Technology (XAUAT, China) and City University London (CUL, UK) have provided facilities for this research. The fly ash used in this research was supplied by Weihe coal power plant (Shaanxi, China). Financial support is received from the project (13JS058) of Education Department of Shaanxi Province (China). All these are gratefully acknowledged.

\section{REFERENCES}

BAKHAREV, T. 2005a. Durability of geopolymer materials in sodium and magnesium sulfate solutions. Cement and Concrete Research, 35, 1233-1246.

BAKHAREV, T. 2005b. Geopolymeric materials prepared using Class F fly ash and elevated temperature curing. Cement and Concrete Research, 35, 1224-1232.

CRIADO, M., FERNANDEZ-JIMENEZ, A., DE LA TORRE, A. G., ARANDA, M. A. G. \& PALOMO, A. 2007a. An XRD study of the effect of the $\mathrm{SiO} 2 / \mathrm{Na} 2 \mathrm{O}$ ratio on the alkali activation of fly ash. Cement and Concrete Research, 37, 671-679.

CRIADO, M., FERNANDEZ-JIMENEZ, A. \& PALOMO, A. 2007b. Alkali activation of fly ash: Effect of the SiO2/Na2O ratio Part I: FTIR study. Microporous and Mesoporous Materials, 106, 180-191. 
CRIADO, M., FERNANDEZ-JIMENEZ, A., PALOMO, A., SOBRADOS, I. \& SANZ, J. 2008. Effect of the $\mathrm{SiO} 2 / \mathrm{Na} 2 \mathrm{O}$ ratio on the alkali activation of fly ash. Part II: Si-29 MAS-NMR Survey. Microporous and Mesoporous Materials, 109, 525-534.

CRIADO, M., PALOMO, A. \& FERNANDEZJIMENEZ, A. 2005. Alkali activation of fly ashes. Part 1: Effect of curing conditions on the carbonation of the reaction products. Fuel, 84, 2048-2054.

FERNANDEZ-JIMENEZ, A., GARCÍA-LODEIRO, I. \& PALOMO, A. 2006a. Durability of alkaliactivated fly ash cementitious materials. Journal of Materials Science, 42, 3055-3065.

FERNANDEZ-JIMENEZ, A. \& PALOMO, A. 2005. Mid-infrared spectroscopic studies of alkaliactivated fly ash structure. Microporous and Mesoporous Materials, 86, 207-214.

FERNANDEZ-JIMENEZ, A., PALOMO, A. \& CRIADO, M. 2005. Microstructure development of alkali-activated fly ash cement: a descriptive model. Cement and Concrete Research, 35, 1204-1209.

FERNANDEZ-JIMENEZ, A., PALOMO, A., SOBRADOS, I. \& SANZ, J. 2006b. The role played by the reactive alumina content in the alkaline activation of fly ashes. Microporous and Mesoporous Materials, 91, 111-119.

HOLMAN, J. P. 2002. Heat transfer (9th Edition), Boston ; London : McGraw-Hill

KOVALCHUK, G., FERNANDEZ-JIMENEZ, A. \& PALOMO, A. 2007. Alkali-activated fly ash: Effect of thermal curing conditions on mechanical and microstructural development - Part II. Fuel, 86, 315322.

LEUNG, C. K. Y. \& PHEERAPHAN, T. 1997. Determination of optimal process for microwave curing of concrete. Cement and Concrete Research, 27, 463-472.

MA, Y., HU, J. \& YE, G. 2013. The pore structure and permeability of alkali activated fly ash. Fuel, 104, 771-780.

METAXAS;, A. C. \& MEREDITH, R. J. 1983. Industrial microwave heating London : Peregrinus on behalf of the Institution of Electrical Engineers

ONG, K. C. G. \& AKBARNEZHAD, A. 2015. Microwave-Assisted Concrete Technology, Taylor \& Francis Group, LLC.

PALOMO, A., ALONSO, S. \& FEMANDEZ-JIMENEZ, A. 2004. Alkaline activation of fly ashes: NMR study of the reaction products. Journal of the American Ceramic Society, 87, 1141-1145.

PALOMO, A., GRUTZECK, M. W. \& BLANCO, M. T. 1999. Alkali-activated fly ashes - A cement for the future. Cement and Concrete Research, 29, 1323-1329.

PUERTAS, F., AMAT, T., FERNANDEZ-JIMENEZ, A. \& VAZQUEZ, T. 2003. Mechanical and durable behaviour of alkaline cement mortars reinforced with polypropylene fibres. Cement and Concrete Research, 33, 2031-2036.

WU, X. Q., DONG, J. G. \& TANG, M. S. 1987. Microwave Curing Technique in Concrete Manufacture. Cement and Concrete Research, 17, 205-210. 